\title{
El arquitecto jesuita Juan Fernández de Bustamante (ca. 1560-1606) y la iglesia parroquial de Lantadilla (Palencia)
}

\section{The Jesuit Architect Juan Fernández de Bustamante (ca. 1560-1606) and the Parish Church of Lantadilla (Palencia)}

Celestina Losada VAREA

CIESE-Fundación Comillas. Avda. Universidad Pontificia, s. n. 39520. Comillas (Cantabria)

losadac@fundacioncomillas.es

ORCID: 0000-0002-9353-9683

Recibido: 05/06/2017. Aceptado: 20/07/2017

Cómo citar: Losada Varea, Celestina: "El arquitecto jesuita Juan Fernández de Bustamante (ca.1560-1606) y la iglesia parroquial de Lantadilla”, BSAA arte, 83 (2017): 47-70.

DOI: https://doi.org/10.24197/bsaaa.83.2017.47-70

Resumen: En este artículo se reconsidera la intervención del arquitecto jesuita Juan Fernández de Bustamante en las construcciones de la Compañía de Jesús en la Provincia de Castilla durante el último cuarto del siglo XVI. El estudio de su participación como tracista en la fachada de la iglesia parroquial de Lantadilla (Palencia) se inserta en el debate acerca del papel de los arquitectos de la Compañía de Jesús como autores de los proyectos o como meros supervisores de las trazas realizadas por los arquitectos laicos.

Palabras clave: arquitectura; Clasicismo; siglo XVI; Compañía de Jesús, Juan Fernández de Bustamante; Vitruvio; Serlio; Vignola; Palencia.

Abstract: This article invites to a reconsideration of the participation of the Jesuit architect Juan Fernández de Bustamante in the projects of the Society of Jesus in the Province of Castile during the last quarter of the $16^{\text {th }}$ century. The study of his participation as a designer in the façade of the parish church of Lantadilla (Palencia) is inserted in the debate about the role of the architects of the Society of Jesus as authors of the projects or as mere supervisors of designs made by lay architects.

Keywords: architecture; Classicism; $16^{\text {th }}$ century: Society of Jesus; Juan Fernández de Bustamante; Vitruvio; Serlio; Vignola; Palencia.

Es objeto de debate el grado de participación que tuvieron los arquitectos jesuitas en la arquitectura de la Compañía de Jesús en España y en otras obras en las que estos se vieron implicados. Subyace en el fondo de esta polémica el 
papel de la propia Compañía en la arquitectura. ${ }^{1}$ Bartolomé de Bustamante, Giuseppe Valeriani, Juan Bautista Villalpando, Andrés Ruiz o Alonso de Tolosa como figuras más significativas dentro de la Orden en la España del siglo XVI, han sido y siguen siendo objeto de discusión. ${ }^{2}$ Por ejemplo, y en relación con la obra del Colegio de San Ignacio en Salamanca, Agustín Bustamante ${ }^{3}$ dice que "es una muestra clara de un intento de la Compañía por hacer arquitectura y la demostración palpable de su incapacidad para desenvolverse en ese terreno”, dirigiendo así la atención, más a los arquitectos laicos que a los de la propia Orden. Se ha cuestionado también el papel de Giuseppe Valeriani como arquitecto; y se ha dicho de Bartolomé de Bustamante que "cultivó la arquitectura no como profesión sino como una afición”. ${ }^{4}$ Alfonso Rodríguez Gutiérrez de Ceballos señalaba que "desgraciadamente, por lo que hace a la arquitectura, y concretamente a España, no abundaban entre los jesuitas del último tercio del siglo XVI los grandes talentos", ${ }^{5}$ sin dejar de admitir que "proyectistas de las iglesias y colegios de la Compañía solían ser, por regla general, los propios jesuitas". ${ }^{\circ}$

La escasa documentación existente acerca de los procesos constructivos de las edificaciones de la Compañía en la Provincia de Castilla explica, quizá, el hecho de que algunos autores hayan privilegiado la autoría de los arquitectos más reconocidos de la propia Orden, o en ocasiones, de arquitectos laicos. ${ }^{7}$ Rodríguez Gutiérrez de Ceballos afirmaba que:

entre los arquitectos propios de la Compañía destacaron en esta primera etapa algunos de auténtica talla, como los padres Bustamante y Juan Bautista Villalpando, y el hermano José Valeriani. (...) Vienen después, en segunda fila, varios aparejadores y maestros de obras de cierto valor, aunque no siempre brillaron con luz propia (...) destacando en la provincia de Castilla, el hermano Juan Fernández de Bustamante. ${ }^{8}$

\footnotetext{
${ }^{1}$ En 1907 Braun y Moisy negaban la existencia de un estilo de los jesuitas. Wittkower / Jaffe (1992): 10-19.

2 Braun (1913). Pirri (1952); (1970). Martín González (1957): 19-40; (1967); (1968): 149-158. Rodríguez Gutiérrez de Ceballos (1967); (1966): 285-321; (2002). Ackerman (1992): 20-29. Bustamante García (1983). Marías (1983). Álvaro Zamora et alii (2012). Criado Mainar (2010): 251-296. Álvaro Zamora / Ibáñez Fernández (2014).

${ }^{3}$ Bustamante García (1983): 244.

${ }^{4}$ Marías (1983): 285.

${ }^{5}$ Rodríguez Gutiérrez de Ceballos (1966): 285-321.

${ }^{6}$ Rodríguez Gutiérrez de Ceballos (1967): 327.

${ }^{7}$ Pereda de la Reguera atribuía a Juan de Nates el diseño de los Colegios de Villagarcía de Campos, Oviedo y Santander. Pereda de la Reguera (1953); (1954):136-175.

${ }^{8}$ Rodríguez Gutiérrez de Ceballos (1967): 328.
} 


\section{JUAN FERNÁNDEZ DE BUSTAMANTE (CA. 1560-1606)}

Los datos ahora conocidos acerca de Juan Fernández de Bustamante nos permiten reconsiderar su trayectoria profesional, como tracista de obras y, como demuestra su diseño para la fachada de la iglesia parroquial de Lantadilla (Palencia), ${ }^{9}$ partidario de una alternativa diferente al vitruvianismo imperante en el panorama arquitectónico del último tercio del siglo XVI.

Braun atribuyó a Fernández de Bustamante la construcción del templo de la casa profesa de Valladolid -actual iglesia de San Miguel-y de la iglesia del colegio de Palencia -Santa María de la Calle-, aunque siguiendo trazas realizadas, a su parecer, por el hermano Juan de Tolosa. ${ }^{10}$ Contradice esta atribución Rodríguez Gutiérrez de Ceballos al dar por segura la mano de Valeriani en el diseño y aseverando que "al hermano Fernández de Bustamante debían faltarle dotes de invención, pues su trabajo se limitó siempre a ejecutar con habilidad las trazas que otros habían compuesto". ${ }^{11}$

Posteriormente se ha documentado su intervención en Villagarcía de Campos, Salamanca (primitivo Colegio), Oviedo, Palencia, Segovia, Monforte de Lemos, Medina del Campo (Colegio de San Pedro y San Pablo) y Autillo de Campos, pero en ninguna se le ha considerado como su tracista, sino tan solo como sobrestante, veedor, tasador, perito o administrador. Al quedar probada la autoría de Fernández de Bustamante en las trazas para la iglesia parroquial de Lantadilla y mencionársele aquí como "tracista de obras", -igual denominación que recibe en Autillo de Campos y en Segovia- es posible apuntar un perfil más preciso sobre este arquitecto jesuita.

\section{1. Su proceso formativo y primeras intervenciones}

JFernández de Bustamante nace hacia 1560 en Villamayor de Treviño (Burgos) $^{12}$ e ingresa en 1577 en el Colegio jesuita de Burgos, en el que permanece hasta su marcha al Colegio salmantino, en el que presumiblemente conocerá al padre Andrés Ruiz. Será éste quien introduzca al joven Fernández Bustamante en las obras de la colegiata de San Luis de Villagarcía de Campos (1579-80) como "hermano coadjutor", recibiendo allí las directrices constructivas de Pedro de Tolosa. ${ }^{13}$ El padre Ceballos afirma que Juan Fernández de Bustamante "figura con frecuencia en los catálogos como

\footnotetext{
9 Archivo Parroquial de Lantadilla (en adelante, APL), Libro de Fábrica, años 1581 a 1614, cuentas del año 1594.

${ }^{10}$ Braun (1913): 76.

${ }^{11}$ Rodríguez Gutiérrez de Ceballos (1967): 74.

${ }^{12}$ Rodríguez Gutiérrez de Ceballos (1967): 73.

${ }^{13}$ Rodríguez Gutiérrez de Ceballos (2010): 314. García Chico cita como ayudantes de Valeriani a los jesuitas Pedro de Hierro, “Juan Fausto", Pedro Salcedo y Juan de la Portilla. García Chico (1955): 43-80; (1957). Tampoco le menciona Martín González (1957): 20-40.
} 
arquitecto, maestro y sobrestante de las obras de varios colegios” y se le describe en 1584 como hombre "de buen ingenio, juicio, prudencia, bastante experiencia, flemático, melancólico. Tiene talento para architecto”. ${ }^{14}$

Ceballos considera a Fernández de Bustamante uno de los seguidores de Ruiz junto con Juan de Tolosa y señala su formación en Villagarcía y su participación en los colegios de Oviedo y Salamanca. ${ }^{15}$ Está documentado que Andrés Ruiz y Juan de Bustamante comparten escenarios y obras, apareciendo vinculados en ocasiones al arquitecto jesuita Alonso de Tolosa. ${ }^{16}$ Por tanto, la formación del jesuita burgalés a la sombra de Andrés Ruiz es más que probable. La mayor parte de las obras en las que Juan Fernández de Bustamante aparece documentado están a cargo de Ruiz "maestro zorro y sabe más de arquitectura de cuantos hay en la Compañia”, ${ }^{17}$ en palabras de doña Catalina de Zúñiga, sobrina del fundador del Colegio de Monforte de Lemos, don Rodrigo de Castro. La obra de este Colegio de Lugo fue una de las muchas empresas constructivas promovidas por la Compañía en la Provincia de Castilla durante el último cuarto del siglo XVI que contaron con la dirección de Andrés Ruiz.

A Juan Fernández de Bustamante se le documenta participando entre 1584 y 1590 en las obras de las Casas de la Compañía de Salamanca, Segovia, Palencia y, tras fallecer Andrés Ruiz (1596), dirigiendo la obra de Monforte de Lemos junto a Juan de Tolosa, quedando él solo al frente de la misma a la muerte de este (1600). ${ }^{18}$ En esos mismos años, entre 1594 y 1603, se le documenta en las iglesias de Autillo de Campos y Lantadilla, así como en la Casa profesa de Medina del Campo. ${ }^{19}$

Entre 1584 y 1590 está documentada la presencia de Juan Fernández de Bustamante en la obra de la actual iglesia de Nuestra Señora de la Calle en Palencia, "uno de los grandes enigmas de la arquitectura de la zona". ${ }^{20}$ Allí reside cuando en 1594 se le reclama para dar la traza de la fachada de la iglesia

\footnotetext{
${ }^{14}$ Rodríguez Gutiérrez de Ceballos (1967): 74.

${ }^{15}$ Rodríguez Gutiérrez de Ceballos (2010): 314. Desde 1580 Andrés Ruiz está al frente de la obra salmantina, siendo Juan de Nates su ejecutor desde 1589.

${ }^{16}$ A Tolosa se atribuyen proyectos para las iglesias parroquiales de Baltanás y Autillo de Campos, tasada ésta por Juan Fernández de Bustamante en 1597. Se atribuye también a Tolosa la traza del convento de San Francisco (o Santa Ana) en Baltanás, obra realizada por Francisco del Río y tasada por Andrés Ruiz. Redondo Cantera (1991): 12.

17 Rodríguez Gutiérrez de Ceballos (2010): 314. Cotarelo Valledor (1946): 123. Catalina de Zúñiga poseía los tratados de Alberti, Serlio, Vignola y Rusconi. Barbeito Carneiro (1988): 67-83. 18 Bonet Correa (1984): 182. Señala Bonet que "El Padre Bustamante figura en 1593 en Valladolid, en una escritura de concierto con el cantero Juan Antonio Maloja”. Suponía este autor que Fernández de Bustamante "probablemente era pariente del también jesuita Bartolomé de Bustamante”.

${ }^{19}$ Rodríguez Gutiérrez de Ceballos (1967): 73 y 74. No se precisan fechas concretas de estancia de Fernández Bustamante, con excepción de la visita que realiza a la obra en 1601.

${ }^{20}$ Bustamante García (1983): 76. La presencia de Fernández Bustamante en el templo del colegio palentino fue documentada por Rodríguez Gutiérrez de Ceballos (1966): 285-321.
} 
de Lantadilla. ${ }^{21}$ Varios elementos de ambas fachadas coinciden, pero solo la de Palencia permanece formalmente vitruviana. Así, el orden corintio sin pedestales se emplea en Palencia en los dos pisos, y en los entablamentos se tallan dentículos, pero no modillones, dando como resultado una ortodoxia vitruviana que no se da en Lantadilla. Frente al uso del orden corintio heterodoxo, del orden compuesto y del ornamento rústico empleado en Lantadilla, en Palencia se sigue a Vitruvio a través de Serlio.

En esos mismos años, Juan Fernández de Bustamante interviene también en las obras del Colegio de Salamanca que desde 1584 dirigirá Andrés Ruiz como Maestro Mayor. En 1589, la obra está a cargo de Juan de Nates -figura clave en la implantación del clasicismo en el foco vallisoletano- y éste otorga un poder a favor de Fernández de Bustamante en noviembre de ese mismo año, para dar las obras de este colegio a destajo, nombrar contadores y tasadores y recibir y cobrar el dinero a cuenta de la obra. ${ }^{22}$ Posiblemente en esta ocasión solo realizara labores de sobrestante.

En 1585 Andrés Ruiz acude a Segovia a modificar las trazas de Giuseppe Valeriani para la Casa de jesuitas, trazas revisadas por Juan de Herrera ${ }^{23}$, y lo hace acompañado de Juan Fernández de Bustamante. En opinión de Bustamante García, la revisión de las trazas por Herrera demostraría que Valeriani era un aficionado y que Andrés Ruiz era un simple técnico, no un arquitecto, y esto a pesar de que en la documentación "de modo claro y firme se dice que Valeriani da las trazas” ${ }^{24}$ y de haberse señalado que el protagonista del cambio en éstas, pasando de una iglesia de tres naves a una con capillas, fue Andrés Ruiz. ${ }^{25}$

A cargo de la obra segoviana estuvieron sucesivamente Juan Bautista de Gogorza, Diego de Matienzo, y desde 1594 Diego de Sisniega, ${ }^{26}$ quien al contratarla se compromete a ejecutar la ventana de la fachada de la iglesia "con un frontispicio con cornisa conforme a la orden de Vignola”. En 1603 Sisniega cede parte de la obra a Francisco de Vega, obligándose a ir "prosiguiendo en la dicha fabrica conforme a la traça que se le diere de parte del dicho Colegio" y para ello ir "descubriendo canteras y sacando y carreteando piedra y abriendo cimientos y aciendolos"; y mientras tanto, el Colegio se encargaría de llevar a la obra a Juan Fernández de Bustamante y a Pedro de Brizuela "para que dieran traça y condición con que se a de proseguir la dicha fabrica”. ${ }^{27}$ Serán por tanto

\footnotetext{
${ }^{21}$ APL, Libro de Fábrica (1581-1614), año 1594, s. f.

${ }^{22}$ Bustamante García (1983): 246-247.

${ }^{23}$ En 1577 Valeriani daba las trazas, previa consulta con Juan de Herrera, y se enviaban a Roma. La obra se comenzó entonces, paralizándose poco después, y se reinició en 1582, colocándose al frente de la obra Andrés Ruiz hasta 1592. Las trazas fueron enviadas a Madrid en 1582 para que las revisara Herrera. Rodríguez Gutiérrez de Ceballos (1966): 290.

${ }^{24}$ Bustamante García (1983): 81-82.

${ }^{25}$ García Oviedo (2014): 103-128.

${ }^{26}$ Losada Varea (2007): 127-130.

${ }^{27}$ Cortón de las Heras (1990): 962-963.
} 
Juan Fernández de Bustamante y Pedro de Brizuela quienes tracen la fachada de la iglesia que será construida y terminada en 1606 por Diego de Sisniega. ${ }^{28}$

El Seminario de Segovia forma parte de un conjunto de edificios que siguen el modelo de la Colegiata de San Luis en Villagarcía de Campos, convirtiendo así a ésta en prototipo arquitectónico para las construcciones jesuíticas de Castilla. La fachada es el elemento que podría haber trazado Juan Fernández de Bustamante. Pese a la mención a Vignola para la molduración de la ventana, se utiliza en esta fachada segoviana un tipo "de ornamento rústico" propuesto por Serlio en el Libro IV, capítulo V. Juan Fernández de Bustamante se servirá de la misma lámina posteriormente en la iglesia de Lantadilla para mostrar un tipo distinto de ornamento rústico. Lo verdaderamente significativo es el interés por este "ornamento" dominante en la fachada de un edificio religioso.

Desde que Valeriani regrese a Roma en 1588 -año que coincide con el fallecimiento de Alonso de Tolosa-, el jesuita Fernández de Bustamante se encarga de supervisar la obra de reedificación de la iglesia parroquial de Santa Eufemia, en Autillo de Campos (Palencia), costeada por el obispo de Córdoba don Francisco de Reinoso, natural y señor de Autillo, ${ }^{29}$ además de benefactor del Colegio de jesuitas de Palencia, en cuya obra interviene el joven Fernández de Bustamante.

La planta de Autillo deriva de la del Seminario de Segovia, obra en la que estuvo implicado el jesuita, como se ha dicho. El 18 de marzo de 1597, Bustamante tasaba en nombre del promotor la obra realizada en Santa Eufemia por el maestro de albañilería Alonso de Santiago. ${ }^{30}$ Cabe señalar que en la escritura formalizada para esta tasación, se dice que el jesuita "reside en la casa de la Compañía de la ciudad de Palencia, que es maestro y trazador de obras". ${ }^{31}$

No es casual que Juan Fernández de Bustamante interviniera en los procesos constructivos promovidos por Reinoso, cuyos tracistas se desconocen y se vienen atribuyendo a Valeriani, Juan de Nates, Alonso de Tolosa o a Diego de Praves. La atribución a Valeriani de los proyectos de Autillo y de Santa María de la Calle en Palencia ${ }^{32}$ ya ha sido contestada. Miguel Ángel Zalama ${ }^{33}$ apuntó que, sin descartar la intervención de Praves en las trazas de Autillo, no resulta descabellado pensar que la intervención de Juan Fernández de Bustamante en 1597 en la tasación de la obra pudiera indicar un mayor grado de participación.

\footnotetext{
${ }^{28}$ Archivo Histórico Provincial de Cantabria, Protocolos, leg. 1408, ff. 59-60v. Poder de Diego Gómez de Sisniega, ante Juan de Ruiseco.

${ }^{29}$ Andrés (1996): 89-120. Sobre Reinoso véase Castro Sánchez (2001).

${ }^{30}$ Zalama Rodríguez (1990): 72.

${ }^{31}$ Zalama Rodríguez (1995): 217-218.

${ }^{32}$ Rodríguez Gutiérrez de Ceballos (1966): 285-321.

${ }^{33}$ Zalama Rodríguez (1990): 164.
} 
Parece lógico pensar que, habiendo participado el jesuita burgalés en el proceso constructivo de la iglesia de Nuestra Señora de la Calle costeada por Reinoso, el prelado le confiara el proceso de reconstrucción y ampliación de la iglesia parroquial de su localidad natal, Autillo de Campos.

\section{LAS TRAZAS DE JUAN FERNÁNDEZ DE BuSTAMANTE PARA LA IGLESIA PARROQUIAL DE LANTADILLA}

Un manuscrito conservado en la Biblioteca Nacional y redactado por el párroco Tomás Alonso Polo hacia $1780^{34}$ describe el templo de Lantadilla y su patronazgo real, representado aquí con la presencia de sendos escudos de Felipe II en la fachada:

Lantadilla tiene un famoso templo, en el que se venera a María Santísima en su Asunción. Según la tradición su primer templo fue obra del rey Godo Theodoredo, por los años 440. Luego el actual fue reedificado en el año de 1570, de orden del Señor Carlos V Emperador de Alemania y I de España, quien comisionó para preservarla a uno o dos ascendientes del Señor Conde Villariezo. ${ }^{35}$

La iglesia de Nuestra Señora de la Asunción en Lantadilla ${ }^{36}$ conserva su fábrica gótica de finales del siglo XV en los dos primeros tramos de la nave central (fig. 1), núcleo del que partiría la obra realizada entre 1575 y 1610 y que supuso el cambio de las formas desde el tardogótico al clasicismo. La transformación del templo tuvo lugar en dos etapas acometidas por dos talleres de cantería distintos, con un periodo de letargo constructivo (1587-1594) entre ambas fases.

Una primera intervención (1581-1587) se debe al taller de cantería de Hernando de Lanestosa, ${ }^{37}$ arquitecto y escultor avecindado en Astudillo que acometió la construcción de nuevos tramos cubiertos por crucería en las naves laterales (fig. 2); nuevas bóvedas de los dos primeros tramos de la nave mayor; y posiblemente, la obra de la torre, todo ello intentando conciliar con el estilo original del templo. En el mes de septiembre de 1587 se pagaba a Lanestosa por "apear el coro y derribar el sobrecoro, apear las cimbrias para las capillas, hacer el crucero del portal de la iglesia y cerrar el hastial de las capillas sobre el arco" y "otros siete mil mas por cubrir las dos capillas mayores del cuerpo de la yglesia”. ${ }^{38}$

\footnotetext{
${ }^{34}$ Vicente Renedo (1993): 25-26.

${ }^{35}$ Probablemente fuera este ascendiente el regidor de Burgos Francisco de Lantadilla Riaño.

${ }^{36}$ La obra gótica y tardogótica en Zalama Rodríguez (1990); (1993).

${ }^{37}$ Quizá emparentado con los canteros del mismo apellido activos en Salamanca. Sobre éstos, Casaseca Casaseca (1975).

${ }^{38}$ APL, Libro de Fábrica (1581-1614), año 1587, s. f.
} 


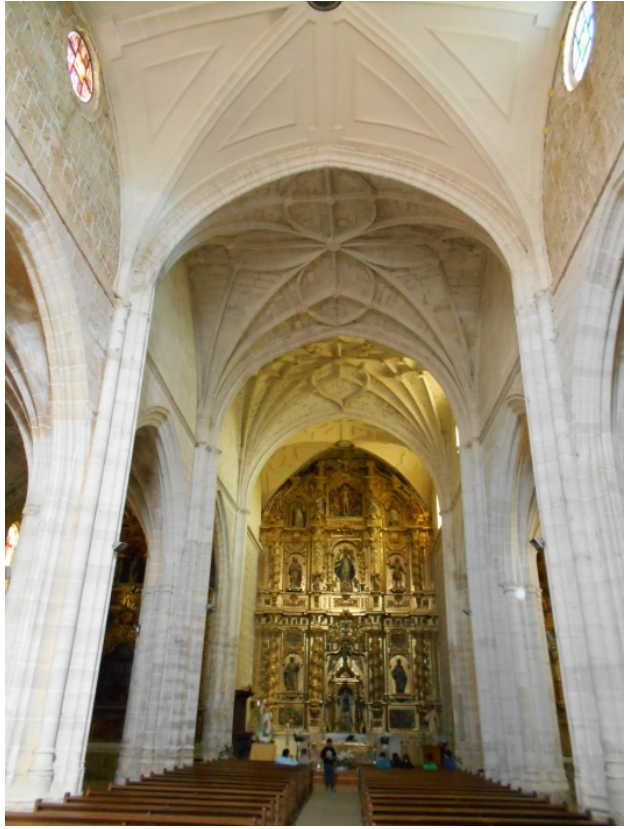

Fig. 1. Interior del templo: nave central. Siglos XV y XVI. Iglesia de la Asunción. Lantadilla (Palencia).

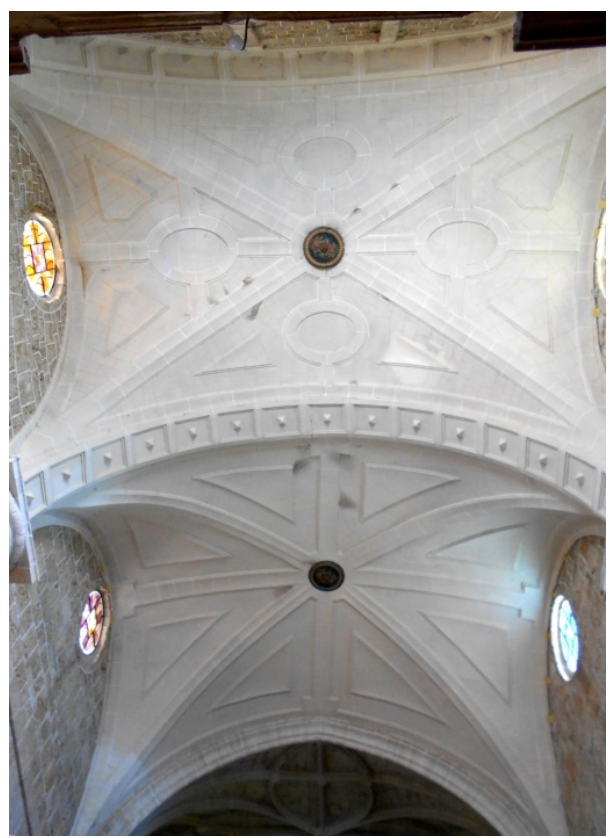

Fig. 2. Bóvedas de los tramos de los pies. Taller de Lanestosa, con modificaciones en el siglo XVIII.

Es difícil precisar la época de construcción de la torre de la iglesia, adosada a la fachada principal (fig. 3) y cuyo diseño se ha supuesto de Juan de Escalante. $^{39}$ En su primer cuerpo se disponen columnas y retropilastras, siguiendo en ello a Alberti, con los grabados de la edición de Cosimo Bartoli (L'Architettura di Leon Batista Alberti, Venezia, Francesco Franceschi, 1565), reproducidos en Los Diez Libros de Architectura de Leon Baptista Alberto. Traduzidos de Latin en Romance (Madrid, Alonso Gómez, 1582). Hace referencia al Libro Sexto, capítulo XII, pp. 185-186, donde describe Alberti varias maneras de relacionar la columna con el muro, aunque aquí se opta por situar las columnas por delante de pilastras. En el siguiente capítulo Alberti dice que "en toda la arte de edificar ciertamente el principal ornamento esta en las columnas, porque muchas puestas juntamente adornan el portal, la pared y todo genero de abertura”, lo que coincide con la valoración de la columna en la base de la torre, la cual ha de ser posterior a 1565, fecha de la publicación de los grabados de Alberti en Italia. Descartamos la opción de que dependa de la edición española de 1582, puesto que no consta ninguna mención a la obra de la torre en la fase constructiva del taller de Lanestosa recogida en el libro de fábrica.

${ }^{39}$ Zalama Rodríguez (1990): 141-143. 


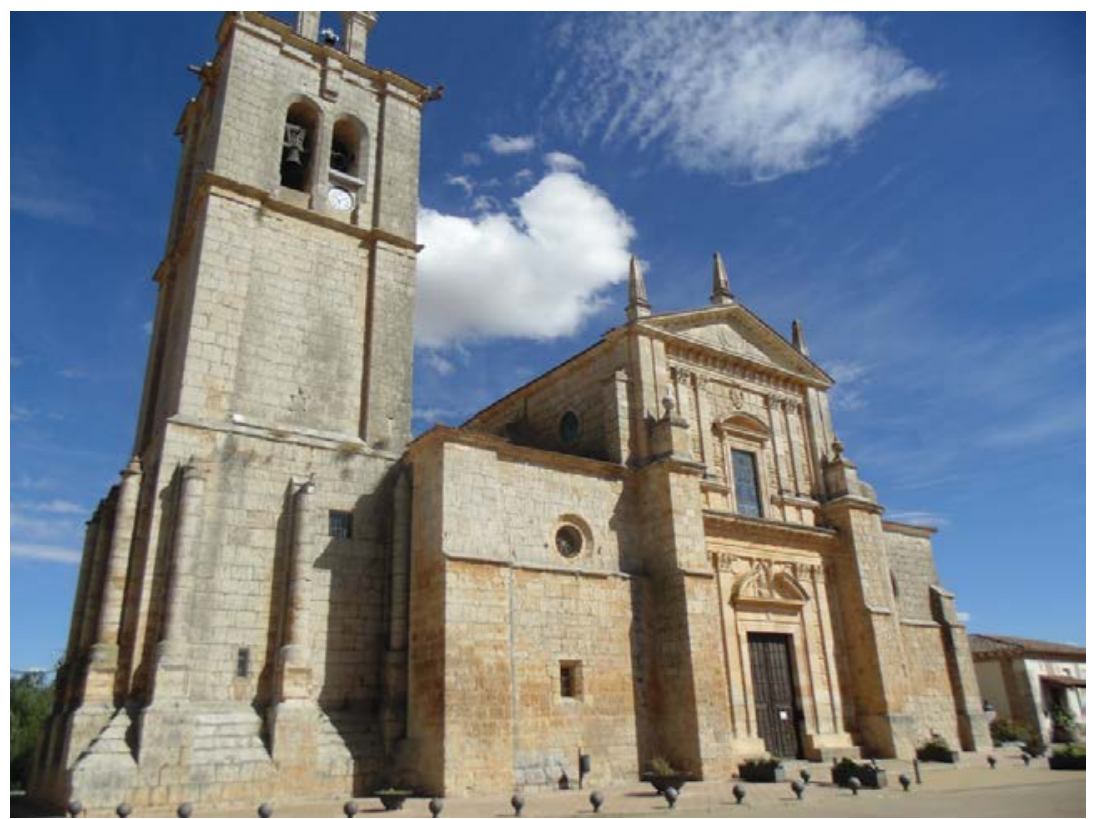

Fig. 3. Iglesia de la Asunción. Fachada principal y torre. Lantadilla (Palencia).

Desde el momento en el que este taller da por terminado su contrato en la iglesia de Lantadilla en septiembre de 1587 y hasta el mes de septiembre de 1594 -en que se reinician con el taller trasmerano liderado por Francisco Gómez del Río- se realizaron obras menores en el interior del templo. ${ }^{40}$ En la primavera de 1594 el párroco Gerónimo Gallego realizó varios viajes a la capital palentina a negociar en el Provisorato la continuidad de las obras. Entre los gastos anotados por este concepto, se constata que uno de los motivos de su consulta con los Provisores de Palencia fue "para informarse de frai Juan de Bustamante teatino traçador de obras, para que viniese a ver la obra de la yglesia desta villa y diera traza con la que proseguirla”, mencionándose entonces que residía en la casa profesa de Palencia. ${ }^{41}$

A la importancia del dato que documenta a Juan Fernández de Bustamante como autor de la traza para la fachada principal de esta iglesia, debemos añadir la significativa mención a su condición de "traçador de obras", lo cual confirma que para entonces ya había realizado otros proyectos.

Consta igualmente anotado en este libro de fábrica el cargo por la compra en Palencia de "seis pliegos de papel de marca mayor para traçar el maestro de la obra" ${ }^{42}$ y el descargo en el mes de agosto de 1594 de "cien reales que se pagaron a fray Juan de Bustamante de la Compañya por tres dias que se detubo

\footnotetext{
${ }^{40}$ APL, Libro de Fábrica (1581-1614), s. f.

${ }^{41}$ APL, Libro de Fábrica (1581-1614), año 1594, s. f.

${ }^{42}$ Losada Varea (2007): 131.
} 
en esta villa a açer la traça de la portada de la yglesia”. En el folio siguiente se anota otro descargo de 793 maravedíes "que hiço de gasto con el dicho teatino y con francisco del rrio y Domingo de Cerecedo canteros por tasar la piedra vieja y nueva de la dicha obra". ${ }^{43}$

Se anotan también los gastos de otros dos viajes a la capital palentina para "tratar las condiciones y traças de la dicha obra ante su señoria el obispo de Palencia con el maestro de cantería francisco del rio, y la otra vez en la sede bacante a contradecir ante los probissores que la dicha obra no se diese al dicho francisco del rrio a tasación como el tenía pedido sino a maestria como el cabildo del lugar pedia". ${ }^{44}$

Esta cuestión del remate de la obra a tasación o a maestría fue el caballo de batalla de la iglesia durante el proceso de contratación de la obra. Se encuentra escrito al margen del Libro de Fábrica: "adviertase que si esta obra se tomare a tasación por canteros que sea por quenta de quien tomare la dicha obra y no de la yglesia”, anotándose también el pago al secretario de Palencia Juan de la Rúa por el auto que hizo para que "la dicha obra se tomase a maestria y no a tasación” ${ }^{45}$ Incluso, en su intento de amarrar bien el contrato con Gómez del Río, el párroco de Lantadilla se desplazó a Baltanás para "informarse de las fianzas que podía dar Francisco del Río maestro de la obra si acaso se le diese a tasación, como se le dio...”. ${ }^{46}$

Francisco del Río trabajaba en esos años en tierras palentinas (Fombellida, Dueñas, Castroverde, Mucientes, Gallegos, Saldaña, Cevico de la Torre, Baltanás, etc.), teniendo además a su cargo la obra del puente de Lantadilla desde 1591. Probablemente la necesidad de continuar la obra de la iglesia aprovechando la presencia en la villa de este excelente taller de cantería trasmerano sea la razón de que se le adjudicara la obra directamente de 1594, aceptándose la condición por él impuesta de que fuera a tasación y no a maestría. ${ }^{47}$

Gómez del Río pertenece a la segunda generación clasicista activa en el foco vallisoletano. Con Juan de Nates, Diego y García de Sisniega, Juan de Mazarredonda, Juan de las Suertes y Felipe de la Cajiga compartió obras,

\footnotetext{
${ }^{43}$ APL, Libro de Fábrica (1581-1614), año 1594, s. f.

${ }^{44}$ APL, Libro de Fábrica (1581-1614), año 1594, s. f.

${ }^{45}$ APL, Libro de Fábrica (1581-1614), año 1594, s. f.

${ }^{46}$ En Baltanás tenía Francisco del Río a su cargo la obra de la iglesia parroquial de San Millán y el convento franciscano de Santa Ana, Zalama Rodríguez (1990): 73-75 y 304-308. Sobre la intervención de Francisco del Río en el monasterio de Baltanás, véase Redondo Cantera (1991).

47 Zalama Rodríguez (1990): 307. Confunde este autor al Francisco del Río, natural de Bádames (Voto) y fallecido en Almanza (León) en 1597, con el maestro homónimo y natural de San Miguel de Aras (Voto) que participa en las obras de El Escorial y en el foco vallisoletano en fechas coetáneas. Es comprensible la confusión entre ambos porque comparten obras, destajos, cesiones y, muy posiblemente, vínculos familiares. El Francisco del Río activo en las obras escurialenses fallece en 1582. Las más completas biografías sobre ambos maestros en González Echegaray et alii (1991): 571-573.
} 
remates, poderes y destajos antes de fallecer en 1598. Firmó las trazas para el puente mayor de Palencia con Alonso de Tolosa y Juan del Ribero Rada (1584); con Domingo de Cerecedo para el proyecto del puente de Herrera de Pisuerga (1590); y dos años después con Juan Gutiérrez de Buega para las "casas episcopales" del obispo de Palencia Fernando Miguel de Prado, sobre las que se interpuso un pleito que fue resuelto en $1595 .{ }^{48}$

Entre el verano de 1594 y el de 1595 se suceden los pagos por la saca de piedra de Torres y de Villaescusa y su labra para la "portada" de la iglesia, interviniendo en ello Domingo de Zorlado, Juan de la Riva y Antonio Martínez, mencionándose entonces el pago de "dos columnas de piedra para la portada", columnas que identificamos con las que pueden verse desde el interior de la iglesia, como apeo del arco embutido en el paramento de la fachada. El 3 de mayo de 1596 Gómez del Río otorgó un poder en favor de Andrés de Zorlado, Francisco Martínez de Valcava, Andrés de Buega, Sebastián de Alvear y Bartolomé Andina, para que en su nombre terminaran la obra "de cantería, albaneria y carpintería” que tenía a su cargo en la iglesia de Lantadilla, "conforme las trazas y condiciones con que yo me concerté y estoy obligado". ${ }^{49}$

Francisco Martínez de Valcava ${ }^{50}$ había sido hasta ese momento el parejador de Gómez del Río y era yerno del maestro homónimo (Francisco del Río), maestro oriundo de Voto que participó en El Escorial en 1576 y realizó abundantes obras por la Meseta Norte, cediendo concretamente en Gómez del Río la de la iglesia palentina de Cevico de la Torre en $1580 .{ }^{51}$ Valcava se hará cargo de la obra de la iglesia de Lantadilla hasta su finalización en 1610, apareciendo en el libro de fábrica como "Maestro de la obra". El 29 de junio de 1597 está fechada la carta de pago que aparece mencionada en el libro de fábrica por los jornales de "172 obreros que trabajaron en la dicha portada" de Lantadilla bajo la dirección de Valcava. Ese año fallecerá Francisco del Río en León y en octubre de 1598 su viuda otorgaba desde la Junta de Voto un poder a favor del arquitecto Felipe de la Cajiga para que terminara las obras que su difunto marido dejó comenzadas, pero Cajiga estaba entonces encarcelado en Valladolid, falleciendo dos días después de otorgado dicho poder.

La finalización de la fachada -en el frontón figura inscrito “AÑO D. 1600”- le permitiría a Juan Fernández de Bustamante en 1601 visitar la obra del

\footnotetext{
${ }^{48}$ Archivo Histórico Provincial de Palencia, Protocolos, leg. 10607, s. f., ante Pedro Vaca. Noticia de pleito, 29 de noviembre de 1595. La demanda contra los bienes que dejó el obispo a su fallecimiento fue retirada por los maestros tras arreglar cuentas con el cabildo palentino en noviembre de 1595.

${ }^{49}$ González Echegaray et alii (1991): 572-573.

${ }^{50}$ Sobre Martínez de Valcava, González Echegaray et alii (1991): 387-388. Este maestro, al que también encontraremos citado como "Balcaba" o "Balcava", firma en varias ocasiones en el libro en recibís a sus trabajos en la iglesia y siempre lo hace con "Valcava", por lo que consideramos que esa es la verdadera grafía de su apellido.

${ }^{51}$ García Chico (1940): 25.
} 
colegio de San Pedro y San Pablo de Medina del Campo (actual iglesia de Santiago el Real), por orden del padre provincial. ${ }^{52} \mathrm{Al}$ año siguiente se anota en el libro de fábrica de Lantadilla el descargo de "100 reales que se dio a Bustamante teatino por la traza que dio del coro" de la iglesia, ${ }^{53}$ coro que actualmente no existe. Unos meses después, ya en 1603, se documenta de nuevo la presencia de Juan Fernández de Bustamante en Lantadilla para tasar en nombre de la iglesia la obra de la "portada y capillas" que había realizado Francisco Martínez de Valcava. ${ }^{54}$ Ese mismo año, Bustamante marcha a Segovia para ponerse al frente de la obra del Colegio de la Compañía en el que, presumiblemente, dará las trazas para la fachada de la iglesia que realiza y concluye en 1606 Diego de Sisniega, como se ha mencionado. En el mes de mayo de ese mismo año, Juan Fernández de Bustamante da trazas y condiciones para un importante edificio, esta vez de carácter civil, en Valladolid. ${ }^{55}$ Será su primera obra de este tipo conocida hasta ahora y su último proyecto arquitectónico, pues fallece ese mismo año en la casa profesa de la Compañía de esa ciudad. ${ }^{56}$

Cuatro años después, Martínez de Valcava termina la obra de la cabecera de la iglesia de Lantadilla probablemente con trazas elaboradas previamente por el arquitecto jesuita, aunque no podamos asegurarlo.

\section{1. Vignola como alternativa a Vitruvio en la fachada de Lantadilla}

La fachada de la iglesia parroquial de Lantadilla (fig. 4) diseñada por Juan Fernández de Bustamante adquiere un carácter monumental al estructurarse en dos pisos articulados mediante órdenes clásicos, de cuatro pilastras y dos medias pilastras en cada uno de ellos, siguiendo un módulo para cada pilastra de 60 centímetro de ancho (dos pies). Si las pilastras ocuparan también el espacio de la puerta, tendríamos una fachada ideal octástila, de pilastras de 2 pies de ancho, con un intercolumnio menor que el picnóstilo (diámetro y medio) lo que da idea de la monumentalidad pretendida, condicionada por el pie forzado al que tuvo que adaptarse el arquitecto jesuita a la hora de trazarla. ${ }^{57}$

\footnotetext{
${ }^{52}$ Rodríguez Gutiérrez de Ceballos (1967): 73 y 74. El Colegio fue fundado en 1551 y las obras del "cuarto nuevo" se prolongaron hasta 1602. La iglesia no deja ver ninguna posible participación de Juan Fernández de Bustamante.

53 APL, Libro de Fábrica (1581-1614), año 1602, s. f.

${ }^{54}$ APL, Libro de Fábrica (1581-1614), año 1606, s. f.

${ }^{55}$ Un reciente hallazgo sobre el que ya estamos trabajando nos documenta al jesuita Juan Fernández de Bustamante como el autor de las trazas de un importante edificio de carácter civil en Valladolid en 1606 y para el que elaboró trazas y condiciones.

${ }^{56}$ Rodríguez Gutiérrez de Ceballos (1967): 74.

${ }^{57}$ Para entonces estaban ya construidos los dos tramos de los pies de las naves que flanquean la portada, así como la torrecilla de la escalera de caracol que daría acceso al desaparecido coro y la torre de campanas adosada en su lado del Evangelio.
} 


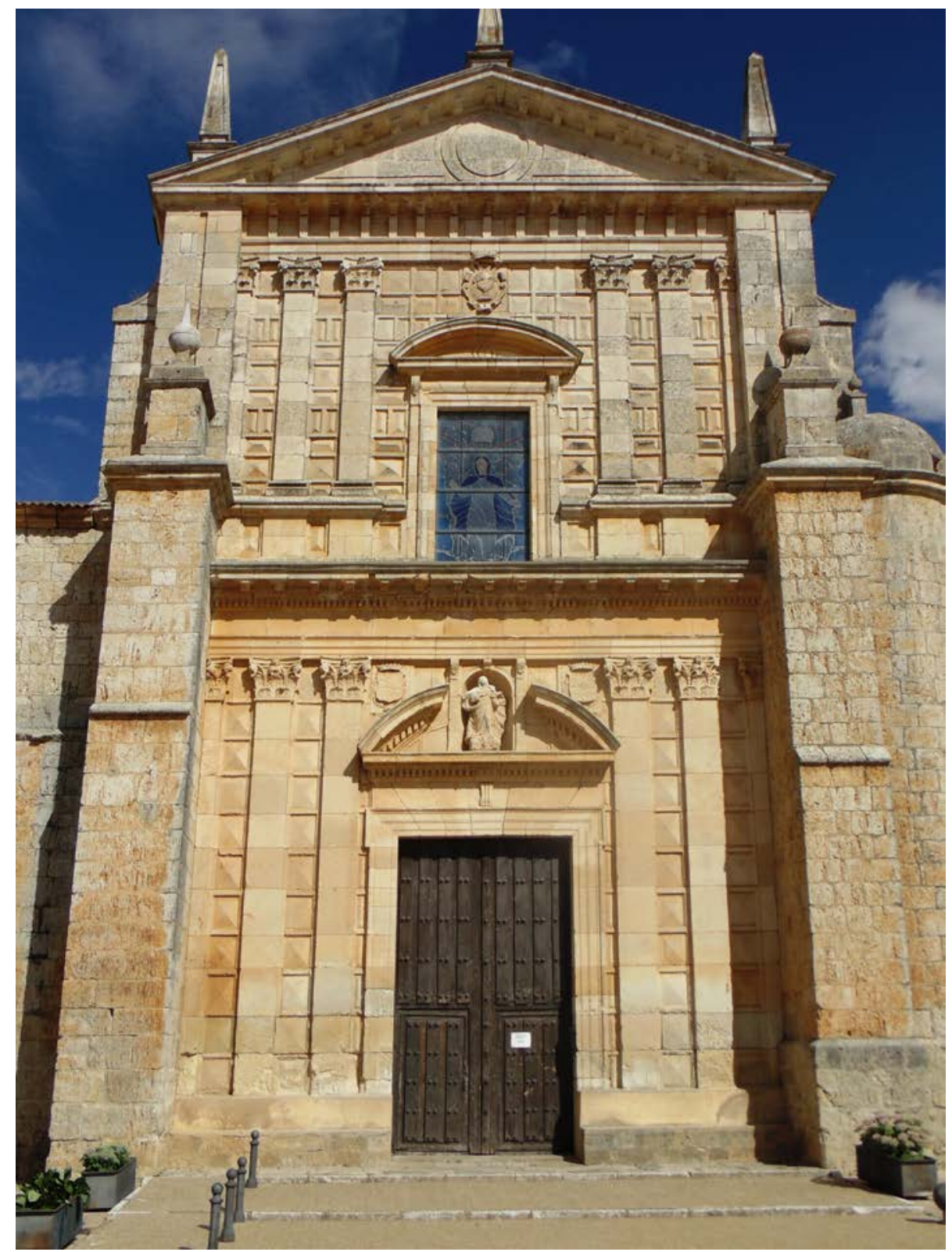

Fig. 4. Fachada principal. Iglesia de la Asunción. Juan Fernández de Bustamante. 1595. Lantadilla (Palencia)

Juan Fernández de Bustamante muestra una alternativa al vitruvianismo impulsado por los arquitectos de la Corte. Explora nuevas vías basándose en Vignola y Serlio, eligiendo de éstos las novedades que se salen de la norma 
vitruviana. Se emplean los órdenes corintio (piso inferior) y compuesto (piso superior), y el ornamento rústico con puntas de diamante. Ni el muro rústico ni el orden compuesto fueron elementos tratados por Vitruvio y el orden corintio es empleado aquí contradiciendo explícitamente lo escrito por Vitruvio en cuanto al entablamento; y lo mismo respecto a los elementos del frontón. Pero la tratadística ya advertía que el rústico podía combinarse con los otros órdenes. Serlio (traducción de Villalpando, Toledo, 1552, capítulo V) dice: "Han sido de parecer los antiguos Romanos que se pueda mezclar con la orden Rustica, no solo la Dorica, mas la Ionica, y también la Corinthia”. Y para ello se escoge del ornamento rústico una de las variantes de mayor riqueza ornamental. Las fuentes utilizadas son los tratados de Jacopo Barozzi da Vignola (órdenes corintio y compuesto) y Sebastiano Serlio (ornamento rústico).

La utilización del tratado de Vignola por Fernández de Bustamante para la traza de la fachada de Lantadilla supone una novedad en el contexto artístico castellano del momento. Si bien la primera mención al tratado de Vignola en su versión italiana (Roma, 1562) tuvo lugar en 1590 en las condiciones para la construcción de la capilla del obispo Tello Maldonado en el claustro de la catedral segoviana, ${ }^{58}$ inmediatamente después de traducirse al castellano por Patricio Caxés en 1593 con el apoyo de Juan de Herrera, ${ }^{59}$ la "Regola delli cinque ordini d'Architecttura in 32 tavole", aparece expresamente citada en las condiciones para dos proyectos jesuíticos elaborados por Andrés Ruiz en 1594: el Colegio de Monforte de Lemos (Lugo) ${ }^{60}$ y el Colegio de la Compañía de Segovia. Ese mismo año de 1594, Juan Fernández de Bustamante utiliza este mismo tratado para disponer los ordenes clásicos en la fachada de Lantadilla. En los tres procesos constructivos intervino Juan Fernández de Bustamante y parece estar clara la vía de penetración en Castilla de esta fuente teórica de la arquitectura italiana.

En 1594, bajo la dirección de Andrés Ruiz, Fernández de Bustamante y Pedro de Brizuela elaboran el proyecto para la fachada de la iglesia colegial de Segovia ya aludida, mencionando explícitamente en las condiciones para la ventana del cuerpo superior el tratado de Vignola. ${ }^{61}$ En Monforte, Fernández de Bustamante realiza la tasación de todo lo construido en el Colegio en el año 1600, figurando entonces como Maestro Mayor tras el fallecimiento de Juan de

\footnotetext{
${ }^{58}$ Sobre esa capilla y sus condiciones véase Cortón de las Heras (1990): 663-668. Sobre la secuencia cronológica en la mención explícita del tratado de Vignola véase Losada Varea (2007): 130, n. 340.

${ }^{59}$ Sobre Vignola y España véase Rodríguez Gutiérrez de Ceballos (1985). Marías (2011): 255276.

${ }^{60}$ Cotarelo Valledor (1946).

${ }^{61}$ Algunos arquitectos españoles (Juan Bautista de Toledo, Juan de Herrera, Juan del Ribero Rada, Francisco de Mora, Juan de Naveda, etc.) tenían el tratado de Vignola en sus bibliotecas, en italiano o castellano, y algunos en la edición que reunía este tratado y el de Labacco (Libro de Antonio Labacco Appartenente a l'architettura; edición conjunta de Girolamo Porro, 1576).
} 
Tolosa y con acuerdo a las trazas y condiciones que habían sido dadas por Andrés Ruiz y Veremondo Resta en $1594 .{ }^{62}$

La elección del orden corintio para la fachada de Lantadilla es coherente con la dedicación de la iglesia a Nuestra Señora de la Asunción. ${ }^{63}$ El orden corintio sin pedestales empleado en el primer piso se toma de la lámina XXI de la "Regola delli cinque ordini d'architettura in 32 tavole" 64 de Jacopo Barozzi da Vignola. En esta lámina, la anchura del fuste de la columna, en el imoscapo, es de 2 módulos, con lo que el módulo equivale al radio (en Lantadilla el "radio" de la pilastra es de 1 pie, es decir, unos 28 centímetros). El friso es liso y posee dentículos y modillones, aspecto este último importante porque supone no tener en cuenta las objeciones de Vitruvio y de Serlio.

Sebastiano Serlio dedica el Capítulo Octavo del Libro IV a la presentación "De la orden Corinthia y del ornamento suyo", donde se critica que se empleen al tiempo "dentellones" y "canes" (dentículos y modillones), como precisamente aparecen en Lantadilla:

Algunos architectos Romanos han fabricado o labrado con alguna mas licencia en algunas Cornisas de este genero, los quales no solo hizieron demás desto canes y Dentellones en una misma cornisa, lo qual es cosa muy reprobada de Vitruvio en el quarto libro en el segundo capitulo. Y la razón porque los Dentellones se hacen, es, para que parezcan o ymiten algunas cabeças de quartones o maderas como se vee en las alas de los tejados o en otras cosas boladas de carpintería, a la qual llama Vitruvio Asseris. Y a este mismo propósito se hacen también los canes para contrahacer a las cabeças de las vigas labradas en las carpinterías con algún primor, a las quales también llama Vitruvio Canterii. Y por esta causa estas dos maneras de travazones, para que las paredes estén mejor ligadas, no pueden estar en un mismo lugar. Y ansi digo que para mi ni en mis obras jamas sufriría en una Cornisa, canes y dentellones, sino lo uno o lootro, aunque en Roma y en muchos lugares de Ytalia, destos hierros semejantes ay harta cantidad [...]”.

En el Libro III Serlio describe unos arcos de triunfo en Roma cuyo ornamento "no se conforma con la doctrina de Vitruvio" y en los que sus arquitectos se tomaron "más licencia que devieran". Y dice concretamente de uno de estos arcos que tiene "dentellones y canes, que es cosa muy reprobada por Vitruvio en una cornisa", recomendando no usar los dentellones. Por el contrario, en Vignola encontramos el uso de "canes" y "dentellones" en el entablamento corintio, tanto en su tabla sinóptica de los órdenes como en las

\footnotetext{
${ }^{62}$ Ribera Vázquez (1989): 277-325 y 566-587. Rodríguez Gutiérrez de Ceballos (1998): 613-633.

${ }^{63}$ Serlio por ejemplo lo explica en el capítulo VIII del libro IV, señalando que el orden corintio se debe emplear para templos dedicados a la Virgen María.

${ }^{64}$ Edición príncipe, 1562; $2^{\mathrm{a}}$ ed., 1570; y en las sucesivas se añaden grabados con las “puertas” de Miguel Ángel. En la edición castellana de Patricio Caxesi, de 1593, la lámina tiene la misma numeración.
} 
láminas del orden corintio (láminas XXI a XXIII), donde además el friso aparece liso (fig. 5); pero en la lámina XXVI, con detalle del capitel y entablamento, además de que el friso aparece decorado, lo que le separa de Lantadilla, se representa el sofito, con recuadros con rosetas, lo que permitirá reflejarlo, con algunas diferencias, en Lantadilla. Así pues, Juan Fernández de Bustamante hace caso omiso a las advertencias de Vitruvio y de Serlio, y en cambio ha acudido a Vignola, donde además encontraba la decoración del sofito.

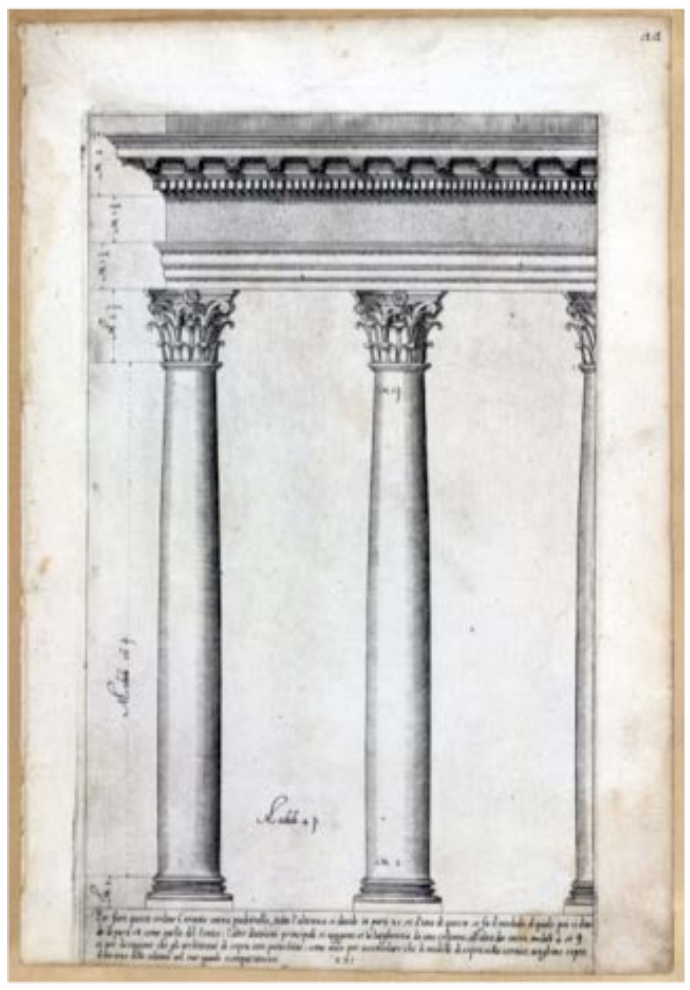

Fig. 5. Modelo de orden corintio. Regola delli cinque ordini d’architettura, lám. XXI. Jacopo Barozzi da Vignola.

Ed. princeps.

Roma, 1562.

Ejemplar conservado en la Biblioteca Nazionale Centrale. Roma.

Los capiteles de esta fachada palentina (fig. 6) se confiaron a Juan de Rozadilla, maestro escultor de origen trasmerano activo en el foco palentino y vallisoletano, siendo esta su obra documentada más temprana. ${ }^{65}$ En Lantadilla el

\footnotetext{
${ }^{65}$ APL, Libro de Fábrica (1581-1614), año 1597, s. f. Estamos ultimando un estudio sobre la obra del escultor montañés avecindado en Palencia y Valladolid Juan de Rozadilla, al que se documenta como autor de la labra de capiteles de la iglesia de Nuestra Señora de las Angustias de Valladolid (1599-1605) y los de la catedral de Valladolid (1627). Intervino junto con Pedro de Torres y Pedro de Cicero en la labor escultórica del sobreclaustro del monasterio de San Zoilo en Carrión de los Condes y en 1612 interviene en la Catedral de Palencia, labrando el retablo y arcosolio funerario de la capilla de San Jerónimo, para dos miembros de la familia del obispo
} 
capitel corintio procede de un modelo común que aparece tanto en las ediciones de Vitruvio como en Serlio, Vignola y otros. Pero los detalles de la flor del ábaco, con sus hojas filiformes y su tallo entrelazado, nos indican que el modelo escogido es el capitel de Vignola (lám. XXVI), aunque se han variado las proporciones, resultando capiteles de menor altura. El mismo modelo de capitel corintio de Lantadilla es el utilizado en la iglesia de Santa Cruz de Medina de Rioseco, en Nuestra Señora de la Calle (Palencia) -que atribuimos a la mano de Rozadilla bajo la dirección de Fernández de Bustamante-, en el interior de la iglesia colegial de Segovia, en Monforte (Lugo) y en la Catedral de Valladolid (donde también trabajó Rozadilla).
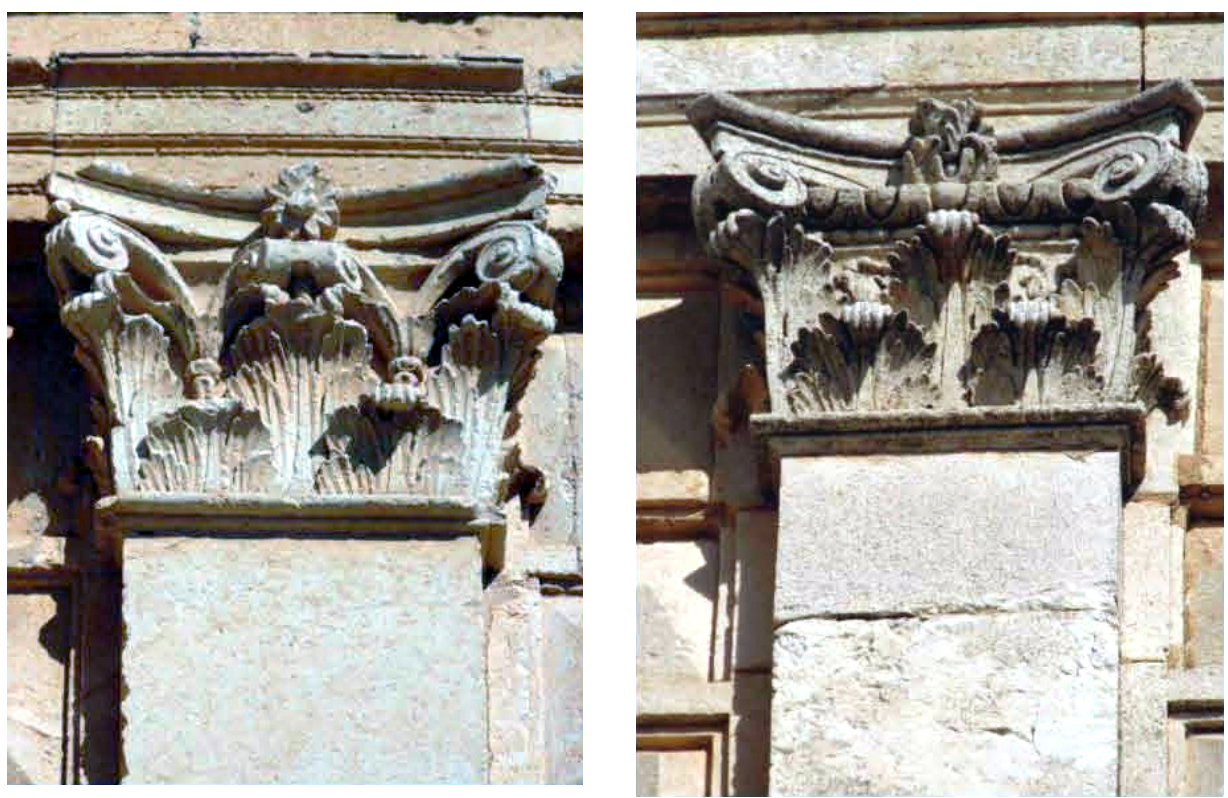

Fig. 6. Capiteles de orden corintio y compuesto en la fachada principal. Juan de Rozadilla. 1597. Iglesia de la Asunción. Lantadilla.

El primer piso de la fachada de Lantadilla incluye la portada en falso dintel formada de tres fajas y un bocel, con orejas; por encima se halla un friso liso, con una ménsula central, y una cornisa con frontón curvo partido. En el tímpano se halla una hornacina con la imagen en piedra de Nuestra Señora de la

Reinoso. Ese mismo año de 1612 se le encarga una imagen para la iglesia parroquial de Santoyo. Realiza varias obras de escultura y ensamblaje para las parroquias de Íscar y Piña de Campos (capilla del doctor Guerra, 1628) y le atribuimos la labra de los capiteles corintios y otras labores de talla de la fachada e interior de la iglesia colegial de Nuestra Señora de la Calle en Palencia. Falleció en Valladolid en 1632. 
Asunción, labrada en 1642. Figuran también en el primer piso sendos escudos de armas de Felipe II, labrados en 1597 por el escultor Pedro de Torres. ${ }^{66}$

La portada ${ }^{67}$ tiene su claro precedente en la de la Colegiata de Villagarcía de Campos, con la diferencia de que en ésta el frontón no está partido y el friso es curvo ("pulvinato", en expresión de Serlio), tipo de friso que es llevado en Lantadilla a la puertaventana del piso superior. Los vanos centrales de esta fachada muestran clara relación con los de las fachadas de Villagarcía de Campos y de Nuestra Señora de la Calle, los cuales son notoriamente idénticos.

Sin embargo, es notoria la ausencia en Lantadilla de los aletones que como en todos estos edificios en los que interviene este arquitecto- unen el cuerpo central de la fachada con los muros contiguos. La explicación puede estar en el posible "pie forzado" que pudo suponer para Fernández de Bustamante, diseñar una fachada que integrara dos contrafuertes ya construidos y una escalera de caracol que daba acceso al coro (actualmente desaparecido), sin olvidar la imponente torre de campanas con la que esta fachada, compartiría su eje visual.

El uso de dentículos en el frontón de la portada de esta iglesia de Lantadilla contradice a Vitruvio, quien en el Libro IV, capítulo II dice: "los Antiguos no aprobaron ni juzgaron aceptable que hubiera en los frontones modillones o dentículos, sino cornisas sencillas”. ${ }^{68}$ Aunque parece evidente la inspiración en Serlio, no podemos descartar las similitudes con la portada corintia con dentículos que aparece en el grabado de los IV Libros de Arquitectura de Palladio (Venecia, 1570). Otro detalle que nos remite a Palladio es el uso en esta fachada de la media pilastra que permite cuadrar el sistema proporcional del espacio entrepilastrado con respecto a las pilastras cajeadas (segundo cuerpo) y los contrafuertes extremos (primer cuerpo)- de manera rigurosa y precisa. ${ }^{6}$

El segundo piso se organiza mediante el orden compuesto sobre pedestales (fig. 7), con el mismo número de pilastras que en el piso inferior. Las pilastras emplean basa ática sobre plinto y pedestal; y los capiteles se toman de Vignola (lám. XXXIII). Nuevamente se trata de algo al margen de Vitruvio, que no se

${ }^{66}$ APL, Libro de Fábrica (1581-1614), año 1597, s. f. Pedro de Torres, que trabaja en varias ocasiones con Rozadilla, fue discípulo de Adrián Álvarez. A él se deben retablos en Palencia y Valladolid; trabajó con Rozadilla en el claustro de San Zoilo de Carrión de los Condes (1604), y en colaboración con Juan Sanz de Torrecilla y su yerno Alonso Núñez labró el tabernáculo del retablo mayor de la catedral de Palencia (1607). Recogido en Losada Varea (2007): 131 y en Portela Sandoval (1977): 383-384.

${ }^{67}$ Es probable la inspiración en Serlio, quien en el libro IV, f. 53, muestra una puerta corintia, tomada del Panteón.

68 "Neque instituerunt in fastigiis denticulos fieri”. Pero Philandrier, por ejemplo, anota ejemplos antiguos con dentículos, como en los frontones del pórtico del Panteón.

${ }^{69}$ No descartamos que el tratado de Palladio en su versión italiana (Venecia, 1570) formara parte de la biblioteca del Noviciado-Colegio de Villagarcía de Campos y que allí pudiera haberlo conocido Juan Fernández de Bustamante. 
ocupó de este orden aunque dejaba la puerta abierta a la existencia de capiteles diferentes a los canónicos.

En cuanto a la superposición de los órdenes, en el Coliseo de Roma se encontraba el ejemplo de superposición de órdenes corintio-compuesto en los dos últimos pisos de la fachada. Y Serlio, que recoge el ejemplo romano, lo emplea en un único modelo de fachada de iglesia (Libro IV, lám. LVI) que titula Templo de Orden Corintio, pero cuyo entablamento del piso superior corresponde al orden compuesto. Y hablando del último orden del Coliseo, Serlio escribe:

posero sopra tutti quest'opera Composita, che così è detta da tutti, benche per quanto si vede, i capitelli sono Corinthii... Ma ponendo i Modiglioni nel Fregio, veniva a far l'opera rica. ${ }^{70}$

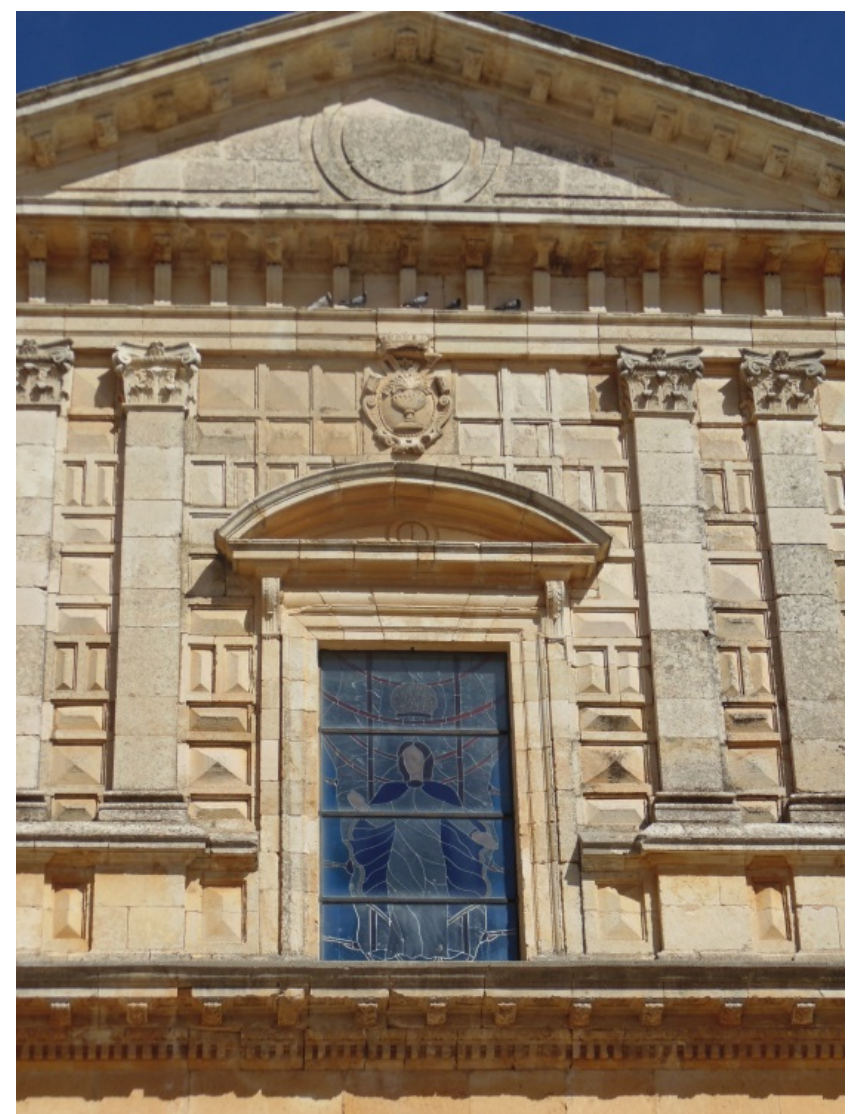

Fig. 7. Fachada principal. Detalle del cuerpo superior de la portada. Iglesia de la Asunción. Lantadilla (Palencia).

${ }^{70}$ Sobre esta propuesta de fachada de iglesia, Zampa (1989): 187-189. 
Por tanto, según este autor, se trataba de un modo de "enriquecer" la fachada de la iglesia propuesta mediante el orden compuesto. Es Serlio quien inventa en el Libro IV el orden compuesto, con personalidad propia, y advierte que "Vitruvio non ragiona in alcun luogo, per mio avviso, di quest'opera Composita". ${ }^{71}$ En la traducción que de él hace Villalpando se habla (Libro IV, capítulo IX) de una "quasi quinta manera de coluna mezclada dellas mismas, aprobada con la autoridad de las obras Romanas antiguas”; y señala que en el entablamento se produjo una innovación al situar "canes" en el friso. Según Serlio, en el Coliseo los canes de este orden se pusieron por estar situado el orden muy arriba, de manera que "no solo hizieron la obra rica, mas ayudaron mucho al vuelo de la corona, y hizieron con esto otra cosa, que el Architrave Friso y Cornija parecía una Cornija sola por los canes que interpusieron en el Friso, de tal manera, que representaron grandeza, y guardaron su proporción admirablemente”. Describe también el orden Compuesto en el Panteón (Libro III, lám. XXXVII) y anota de nuevo la particularidad de los canes en el friso: "cosa por ventura hasta en aquel tiempo no vista". ${ }^{72}$ Estos "canes" del friso son representados también en los grabados de las "Anotaciones" a Vitruvio por Philandrier, pero no en Vignola salvo en un caso muy especial, donde además de los "canes" (ménsulas) del friso, hay modillones bajo la cornisa, mientras que los canes no son lisos (como en Philandrier y en Serlio), sino que llevan "glifos". De este modo, se muestra únicamente en un entablamento "inventado" por Vignola (Regola, lámina XXXII), donde se dispone un arquitrabe con solo dos fajas y canes con glifos (igual que en Lantadilla), entre los que se dejan metopas que van decoradas; además, por encima, sitúa modillones bajo la cornisa. Haber adoptado este entablamento vignolesco en Lantadilla (sin decorar las metopas) prueba una vez más que Juan Fernández de Bustamante se separa de la norma vitruviana, prefiriendo aquí una innovación moderna -de Vignola- que coloca sobre un orden compuesto que está al margen de Vitruvio. Vignola habla de "ordine composito" pero lo entiende en el sentido de "itálico" de Alberti, es decir, como una mezcla de órdenes sin proporciones propias, y reduce su ilustración a tan sólo el capitel. La respuesta, en Lantadilla, será inspirarse en el entablamento "inventado" de Vignola.

Un frontón triangular cubre en esta fachada palentina todo el cuerpo central y el uso en él de dentículos contradice, como ya hemos señalado, a Vitruvio, quien recordaba que para los "Antiguos" (griegos) no era aceptable el uso de modillones o dentículos en los frontones, sino cornisas sencillas. Por encima se hallan tres obeliscos sobre pedestales, inspirados en el que "es en el cerco de Antonio Caracalla” en Roma, representado por Serlio. ${ }^{73}$

\footnotetext{
${ }^{71}$ Citado por Günther (1989): 154-168.

72 Sebastiano Serlio, Tercero y Quarto Libro de Architectura..., traducción de Francisco de Villalpando. Toledo, Juan de Ayala, 1552.

${ }^{73}$ Serlio, traducción de Francisco de Villalpando, libro III, lám. 33, letra “R”.
} 
La elección de Juan Fernández de Bustamante para el tratamiento del muro de esta fachada que se recubre de un ornamento rústico (fig. 8) se mantiene, una vez más, al margen de Vitruvio. Tomado de una lámina de Serlio (fig. 9) en la que se proponen varios modelos (Libro IV, capítulo V), encontramos la descripción teórica de lo que vemos labrado en la piedra: el primer tipo con sillares labrados "gruesamente" (sin desbastar), con juntas "subtiles y delicadas"; y "despues con alguna mas delicadeza dividieron los quadros o sellares con una cuerda mas honda que ellos"; a ello se añadía "labrarlos mas polidamente" y también en forma de "cruzes por arista"; también "quiriendo ymitar diamantes labrados" y el tipo de "forma de diamantes de tabla llanos", y "comunmente se llama esta sellareria Punta de diamante". ${ }^{74}$

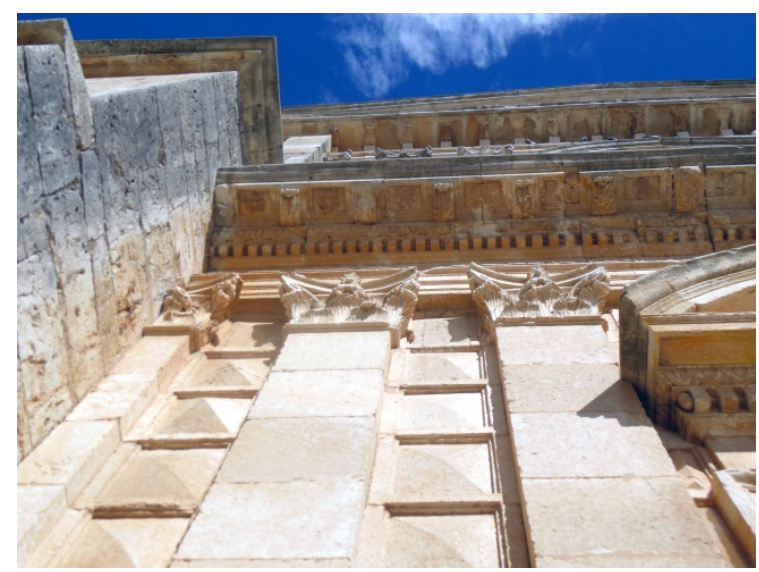

Fig. 8. Detalle del cuerpo superior de la portada. Iglesia de la Asunción. Lantadilla.

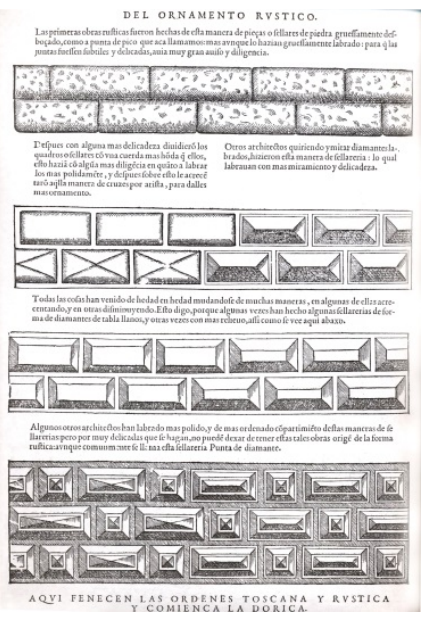

Fig. 9. Libro Qvarto de Architectvra. Sebastiano Serlio. Venecia, 1537 (trad. de Francisco de Villalpando, Toledo, 1552, fol. XVIIIv).

En Lantadilla, donde se emplean los tipos de "cruces por arista" y de "diamantes labrados", el ornamento rústico es empleado para enriquecer la fachada, con el fin de otorgar "ornamento" y "delicadeza” al muro, una función atribuida por Serlio a este ornamento cuando se mezcla con el orden corintio. Y, como dice Serlio, el ornamento rústico alude a la Naturaleza, frente al orden clásico, que alude al Arte.

\footnotetext{
${ }^{74}$ El llamado "bugnato a punte di diamante" era utilizado en Italia (también en España: v.gr., Colegio de Santa Cruz en Valladolid) desde la Edad Media, sin tener un origen clásico. Ghisetti Giavarina (2007-08): 9-26.
} 


\section{BIBLIOGRAFÍA}

Ackerman, James S. (1992): “La Chiesa del Gesù alla luce dell'architettura religiosa contemporánea”, en Rudolf Wittkower / Irma B. Jaffe (eds.): Architettura e arte dei gesuiti. Milán, Electa. pp. 20-29.

Álvaro Zamora, María Isabel et alii (coords.) (2012): La arquitectura jesuítica. Actas del Simposio Internacional. Zaragoza, 9, 10 y 11 de diciembre de 2010. Zaragoza, Institución "Fernando el Católico".

Álvaro Zamora, María Isabel / Ibáñez Fernández, Javier (coords.) (2014): La Compañía de Jesús y las artes. Nuevas perspectivas de investigación. Zaragoza, Universidad de Zaragoza.

Andrés, Gregorio de (1996): "Perfil artístico del palentino Francisco de Reinoso, obispo de Córdoba”, Publicaciones de la Institución Tello Téllez de Meneses, 67, 89-120.

Barbeito Carneiro, María Isabel (1988): “La biblioteca de la VI Condesa de Lemos”, en Varia Bibliographica. Homenaje a José Simón Díaz. Kassel, Edition Reichenberger, pp. 67-83.

Bonet Correa, Antonio (1984): La arquitectura en Galicia en el siglo XVII. Madrid, C.S.I.C.

Braun, Joseph (1913): Spaniens alte Jesuitenkirchen. Friburgo de Brisgovia, Herdersche Berlagshandlung.

Bustamante García, Agustín (1983): La arquitectura clasicista del foco vallisoletano (1561-1640). Valladolid, Institución Cultural Simancas.

Casaseca Casaseca, Antonio (1975): Los Lanestosa. Tres generaciones de canteros en Salamanca. Salamanca, Centro de Estudios Salmantinos.

Castro Sánchez, Marcial (2001): Vida de don Francisco de Reinoso: Obispo de Córdoba y Abad de Husillos (1534-1601). Palencia, Diputación Provincial de Palencia.

Cortón de las Heras, María Teresa (1997): La construcción de la Catedral de Segovia (1525-1607), 3 vols. Segovia. Caja de Ahorros y Monte de Piedad. Segovia.

Cotarelo Valledor, Armando (1946): El Cardenal don Rodrigo de Castro y su fundación en Monforte de Lemos, 2 vols. Madrid, Editorial Magisterio Español.

Criado Mainar, Jesús (2010): “Contribución de la Compañía de Jesús al campo de la arquitectura y de las artes plásticas”, en José Luis Beltrán Moya (coord.): La Compañía de Jesús y su proyección mediática en el mundo hispánico durante la Edad Moderna. Madrid, Sílex, pp. 251-296.

García Oviedo, Cristina (2014): "El Colegio de la Compañía de Jesús de Segovia. Fuentes y metodología de estudio”, en María Isabel Álvaro Zamora et alii (coords.): La arquitectura jesuítica. Actas del Simposio Internacional. Zaragoza, 9, 10 y 11 de diciembre de 2010. Zaragoza, Institución “Fernando el Católico”, pp. 103-128.

García Chico, Esteban (1940): Documentos para el estudio del Arte en Castilla, t. 1: Arquitectos. Valladolid, Universidad de Valladolid, Seminario de Arte y Arqueología.

García Chico, Esteban (1955): “Los artistas de la Colegiata de Villagarcía de Campos”, BSAA, 20, 43-80. 
García Chico, Esteban (1957): La colegiata de Medina del Campo y otros estudios, t. I. Valladolid, Gráficas Andrés Martín.

González Echegaray, María del Carmen et alii (1991): Artistas cántabros de la Edad Moderna. Su aportación al arte hispánico (diccionario biográfico-artístico). Santander, Institución Mazarrasa y Universidad de Cantabria.

Ghisetti Giavarina, Adriano (2007-08): “Il bugnato a punte di diamante nell'architettura del Rinascimento italiano”, Lexicon, 5-6, 9-26.

Günther, Hubertus (1989): "Serlio e gli ordini architettonici”, en Chistof Thoenes (ed.): Sebastiano Serlio. VI Seminario Internazionale di Storia dell'Architettura (Vicenza, 1987). Milán, Electa, pp. 154-168.

Losada Varea, Celestina (2007): La arquitectura en el otoño del Renacimiento. Juan de Naveda (1590-1638). Santander, Universidad de Cantabria.

Marías, Fernando (1983): La arquitectura del Renacimiento en Toledo (1541-1631). Toledo, C.S.I.C.

Marías, Fernando (2011): "Vignola e la Spagna. Disegni, incisioni, letture e traduzioni”, en Anna María Affanni / Paolo Portoghesi (coords.): Studi su Jacopo Barozzi da Vignola. Atti del Convegno (Caprarola, 23-26 ottobre 2008). Roma, Gangemi, pp. 255-275.

Martín González, Juan José (1957): “La Colegiata de Villagarcía de Campos y la arquitectura herreriana”, BSAA, 23, 19-40.

Martín González, Juan José (1967): Arquitectura barroca vallisoletana. Valladolid, Diputación Provincial de Valladolid.

Martín González, Juan José (1968): "Primeras iglesias jesuíticas en Castilla la Vieja”, en España en las crisis del arte europeo. Madrid, C.S.I.C., pp. 149-158.

Pereda de la Reguera, Manuel (1953): Juan de Nates. Santander, Centro de Estudios Montañeses.

Pereda de la Reguera, Manuel (1954): “Miscelánea histórico-artística (noticias y documentos inéditos)", Altamira, 1-3, 136-175.

Pirri, Pietro (1952): Villagarcía de Campos. Evocación histórica de un pasado glorioso. Bilbao, El Mensajero del Corazón de Jesús.

Pirri, Pietro (1970): Giuseppe Valeriani, S.I., architetto e pittore 1542-1596, Roma, Institutum Historicum Societatis Iesu.

Portela Sandoval, Francisco José (1977): La escultura del siglo XVI en Palencia. Palencia, Diputación Provincial de Palencia.

Redondo Cantera, María José (1991): Baltanás. Iglesia de San Millán. Palencia, Diputación Provincial de Palencia.

Ribera Vázquez, Evaristo (1989): Galicia y los Jesuitas. Sus Colegios de enseñanza en los siglos XVI al XVIII. La Coruña, Fundación Barrié de la Maza.

Rodríguez Gutiérrez de Ceballos, Alfonso (1966): "Juan de Herrera y los jesuitas Villalpando, Valeriani, Ruiz, Tolosa”, Archivum Historicum Societatis Iesu, 35, 285-321.

Rodríguez Gutiérrez de Ceballos, Alfonso (1967): Bartolomé de Bustamante y los orígenes de la arquitectura jesuítica en España, Roma, Institutum Historicum Societatis Iesu.

Rodríguez Gutiérrez de Ceballos, Alfonso (1985): Introducción a Iacome de Vignola. Regla de las Cinco Ordenes de Architectura. Valencia, Albatros. 
Rodríguez Gutiérrez de Ceballos, Alfonso (1998): "El cardenal don Rodrigo de Castro, humanista y mecenas de las Artes”, en Antonio Eiras Roel (coord.): El Reino de Galicia en la Monarquía de Felipe II, Santiago de Compostela, Xunta de Galicia, pp. 613-633.

Rodríguez Gutiérrez de Ceballos, Alfonso (2002): La arquitectura de los jesuitas. Madrid, EDILUPA.

Rodríguez Gutiérrez de Ceballos, Alfonso (2010): "La arquitectura jesuítica en Castilla. Estado de la cuestión”, en María Isabel Álvaro Zamora et alii (coords.): La arquitectura jesuítica. Actas del Simposio Internacional. Zaragoza, 9, 10 y 11 de diciembre de 2010. Zaragoza, Institución “Fernando el Católico”, pp. 305-325.

Vicente Renedo, Mederico (1993): Lantadilla. Su historia, su arte, sus gentes. Palencia, Diputación Provincial de Palencia.

Wittkower, Rudolf / Jaffe, Irma B. (eds.) (1992): Architettura e arte dei gesuiti. Milán, Electa.

Zalama Rodríguez, Miguel Ángel (1990): La arquitectura del siglo XVI en la provincia de Palencia. Palencia, Diputación Provincial de Palencia.

Zalama Rodríguez, Miguel Ángel (1993): Lantadilla. Iglesia de la Asunción. Palencia, Diputación Provincial de Palencia.

Zalama Rodríguez, Miguel Ángel (1995): "Documentos de Historia del Arte en Palencia I. Arquitectos y edificios del siglo XVI”, Publicaciones de la Institución Tello Téllez de Meneses, 66, 66-320.

Zampa, Paola (1989): "Proporzioni ed ordini nelle chiese del Serlio", en Chistof Thoenes (ed.): Sebastiano Serlio. VI Seminario Internazionale di Storia dell'Architettura (Vicenza, 1987). Milán, Electa, pp. 187-189. 